Ruhe kommen, dann werde ich wo möglich meine gewohnten Studien fortsetzen.

In allem Uebrigen verweise ich auf die nun folgenden Beiträge, welche meine eigenen Beobachtungen sind.

(Fortsetzong folgt.)

\title{
Zusätze und Berichtigungen
}

zu dem Aufsatze ,die im Umanschen Kreise in den Jahren 1867, 1868 und 1869 beobachteten Vögel“**) nach Beobachtungen gemacht im Jahre 1870.

Von

Forstmeister H. Goebel.

(Siehe März-Heft S. 151.)

[10.] Chloris vulgaris.

Am 7. Juni fand ich das Nest auf einer Hainbuche $3^{\prime}$ hoch mit 5 schwach bebrüteten Eiern.

Maasse: Länge $20-19-20-19$; Breite $14-14-14-14 \mathrm{Mm}$.

[13.] Miliaria valida.

War in diesem Jahre (70) recht häufig vertreten, in feuchten Niederungen sich aufhaltend.

197. Emberiza cirlus, Zaunammer.

Den 28. Mai fand ich das Nest etwa $1^{\prime}$ hoch mit 3 frischen Eiern.

Maasse : Länge $21-21-20$; Breite 16-16-16 $\mathrm{Mm}$.

198. Melanocorypha calandra, Kalanderlerche, beobachtete ich an der Chersonschen Grenze am 14. September in einem Flug von 30 Stück.

[31.] Falco peregrinus.

Ist nicht so selten als Brutvogel, wie ich bisher annahm; ich fand in diesem Jahre 3 Gelege, am 19., 22. und 24. April.

Maasse: 1) Länge 52-50-51; Breite 40-40-38 Mm.

2) Länge $49-50-49-49 \mathrm{Mm}$; Breite $39-40-39-39 \mathrm{Mm}$.

3) Länge 50-51-49; Breite 39-40-38 Mm.

[43.] Haliaetus albicilla,

habe ich in 2 Paaren in diesem Jahre als Brutvogel beobachtet. Am 19. April fand ich den Horst mit 2 schwach bebrüteten Eiern,

*) Bei den bisher beobachteten Vögeln führe ich dic alte Nummer in Klammer an, bei den neu hinzukommenden die fortlaufeude des Bugisters. 
am 3. Mai bestieg ich den andern und land 3 Junge darin. Der Horst war eine vollständige Schlachtbank, es fanden sich, ausser 2 jungen entengrossen Gänsen, Reste von Fischen, Hühnern und Enten vor.

Maasse: Länge $72-71 ;$ Breite $5 \nmid-57 \mathrm{Mm}$.

[46.] Milvus regalis.

Auch ron diesem Raubrogel fand ich in diesem Jahre den Horst am 6. Mai mit 2 frischen Eiern.

Maasse: Länge 60-50; Breite 45-42 $\mathrm{Mm}$.

[39.] Aquila fulva ist wohl chrysaetus, wenigstens ein getödtetes Exemplar musste ich als Goldadler anerkennen. -

[199.] Scops zorca, $Z$ wergohreule.

Den 16. Juni fand ich den Horst in einem hohlen Baum and fing das sehr fest sitzende Weibchen über den 3 Eiern.

Maasse: Länge 30-28-32; Breite 27-27 - $26 \mathrm{Mm}$.

[52.] Brachyotus vulgaris.

War sehr häufig in diesem Jahre, besonders im Herbst lagen im Umkreise oft $5-6$ zusammen.

200. Strigiceps pallidus, Steppenweibe.

Am 7. September schoss ich ein $\delta$ an der Chersonschen Grenze.

[74.] Ruticilla phoenicura.

Ich fand in diesem Jahre mehrere Nester dieses Vogels, urstes am 20., letztes am 31. Mai.

Maasse: Länge D. 19 Mx., 19 M., 18 Mm.;

Breite $14 \quad 14 \quad 13 \mathrm{Mm}$;

Spurei 14 Mm. Länge, 11 Mm. Breite.

[80.] Turdus viscivorus.

Am 2. Mai fand ich das Nest dieser Drossel mit 4 recht stark bebrüteten Eiern.

Nestmaasse: Aeusserer Durchmesser 150, innerer 100.

Aeussere Höhe 100 , innere 60 ).

Nestmaterial: Trockne Grashaline und Wurzelfasern, Unterbau aus feuchter Erde, in die Wandungen war keine Erde gemischt.

Standort: $6^{\prime}$ hoch, auf eincr Hainbuche, an den Stamm sich lehnend, in einer düstern Waldpartie, am Rande einer tief liegenden schmalen Wiese.

Maasse: Länge 29-29-29-30; Breite $22-23-23-22 \mathrm{Mm}$. [94.] Hypolais hortensis.

Am 2. Juli fand ich das Nest dieses bis hinzu von mir nur 
einmal auf dem Zuge beobachteten Vogels mit 5 bebrüteten Eiern. Das Nest stand im nördlichsten meiner Reviere, das an den Swenigorodschen Kreis grenzt und schon einzelne Birken besitzt. Das Nest war, wie immer, mit Birkenbast ausgekleidet, so dass es scheint, dass der Vogel in Folge dieser Gewohnheit an Birkenwälder gebunden ist.

Eiermansse: Länge $19-17-18-17 \mathrm{Mm}$;

Breite 13-14-14-14 Mm.

[95.] Calamoherpe turdoides.

- Ich fand 2 Gelege dieses Vogels im hohen, fingerdicken Rohr, in das amondinacea schon nicht mehr baut.

Nestmaasse: A eusserer Durchm. 94-96, innerer 53-56 $\mathrm{Mm}$. Aeussere Höhe 120-125, innere $60 \mathrm{Mm}$.

Material: Feine Sumpfgräser und Binsenblätter mit etwas Pflanzenwolle.

Neststand: 4 und $6^{\prime}$ hoch, auf Rohrblättern aufsitzend.

Eiermaasse :

1) Länge 22-21 Mm., am 17. Juni frisch.

Breite $16-15 \mathrm{Mm}$.

2) Länge 23-23-23 Mm., am 1. Juli stark bebrütet.

Breite 17-16-17 Mm., 5 Stück (2 zerbrochen).

201. Locustella?

Ich habe an 2 Orten in unserm Kreise, die ich zufällig zum ersten Mal besuchte, eine Locustella-Art in Menge schreien hören, ob naevia oder fluviatilis kann ich nicht mit Bestimmtheit sagen, da es mir nicht gelang; einen der Vögel zu schiessen, ich glanbe aber, dass es eher fluviatilis sein wird. Zuerst gehört am 27. April.

\section{[104.] Agrodroma campestris.}

2 Gelege dieses Vogels gefunden am 17. Juni mit 5 schwach bebrüteten Eiern auf einem öden, sonnverbranuten Weideplatz am Ufer eines Teiches, als Schutz nur eine vielïstige Unkrautstande besitzend; das zweite $\mathrm{Mal}$ in einem undichten Hirsefelde am 25. Juli nit 4 Eiern, die grosse, aber abgestorbene Embryonen besassen, wohl in Folge des bäufigen Regens. Das Weibchen sass aber trotzdem ganz fest und verliess das Nest erst, als ich ganz nahe war.

Maasse: 1) Länge $21-21-22-20-21 \mathrm{Mm}$.

Breite $16-16-16-16-16 \mathrm{Mm}$.

2) Länge $20-20-20-20 \mathrm{Mm}$.

Breite $16-16-15-15 \mathrm{Mm}$. 


\section{[144.] Machetes pugnax.}

In diesem Jahre traf ich am 14. September 3 Exemplare (2 t, 1 o) dieses Vogels in Gesellschaft von 2 Actodroma minuta am Ufer eines kleinen Teiches an, und tödtete mit einem Schuss alle, mit Ausnahme des einen Strandläufers.

202. Numenius arcuatus, Grosser Brachvogel.

Am 2. April 6 Stück beobachtet.

$$
\text { [146.] Totanus glareola. }
$$

Ist Brutrogel unseres Kreises, den ich auf dem Sokolowschen Sumpfe neben flüggen Jungen schoss, die auf dem Kopfe noch einzelne Flaumfedern zeigten.

203. Anthropoides virgo, Jungfernkranich.

Schon im vorigen Jahre beobachtete ich ziemlich spät im Jahre auf einem grossen Steppenheuschlage eines von mir verwalteten Gutes ein Paar Kraniche, doch kam mir virgo gar nicht in den Sinu. In diesem Jahre, als ich das Paar ganz nahe sah, fiel mir die Kleinheit auf und zugleich allerhand Sprünge und Wendungen, die die Vögel machten. Jetzt fiel mir Dr. Brehm's Beobachtung über das sonderbare Benehmen des $G$. virgo während der Brutzeit ein, ich suchte den Heuschlag tleissig ab und hatte die Freude, am 6. Mai das Nest mit 2 frischen Eiern zu finden. In Herbst beobachtete ich noch 4 Kraniche an der Chersonschen Grenze auf einem ähnlichen Heuschlage. Da bei uns alle Steppenheuschlage aufgerissen werden, so wird wohl $G$. virgo, der ja ein echter Steppenvogel ist, bald verschwinden aus unserm Kreise, wie denn Otis tetrax, die früher häufig gewesen sein soll, jetzt nicht mehr zu finden ist.

Maasse: Länge 79-77; Breite 48-50 Mm.

[165.] Crex pratensis.

An 2. Juli das Nest mit 4 frischen Eiern gefunden.

Maasse: Länge 38-37-36-37 Mm.;

Breite 27-28-27-27 $\mathrm{Mm}$.

[166.] Ortygometra porzana.

2 Nester gefunden, am 2. Juni mit 3 frischen Eiern, am 30. Juni mit 8 schwer bebrüteten und einem faulen Ei.

Maasse: 1) Länge 33-33-34; Breite 23-22-24 Mm.

2) Länge 33 ; Breite 24.

204. Mergulus albellus, Zwergsäger.

Am 28. März eine Schaar von 12 Stück auf einem Teiche beobachtet, auf dem das Eis noch nicht vollständig geschmolzen war, auf den Schollen sitzend während eines heftigen Sturmes. 
Zusätze zu den im Umanschen Kreise beobachteten Vögeln. 299

Es kommen also als neu beobachtet hinzu:

Brütende Zugvögel :

$\begin{array}{ll}\text { Emberiza cirlus, } & \text { Locustella? } \\ \text { Scops zorca, } & \text { Anthropoides virgo. }\end{array}$

Durchzugvögel oder zufällig beobachtete:

Melanocorypha calandra ${ }^{*}$ ), Numenius arcuatus,

Strigiceps pallidus, Mergulus albellus.

Aus der Rubrik c. Durchreisende sind unter die Rubrik b. Brütende Zugvögel zu versetzen:
Milvus rufus,
Totanus glareola,
Hypolais hortensis,
Crex pratensis.

Aus der Rubrik $c$ in die Rubrik a Standrögel zu versetzen:

Haliaetus albicilla.

Aus der Rubrik d. Wintergäste in die Rubrik a:

Turdus viscivorus.

\section{Berichtigungen.}

In dem bis jetzt gedruckten und mir zu Handen gekommenen ersten Abschnitt haben sich folgende Fehler beim Drucken oder beim Abschreiben des Manuscriptes eingeschlichen:

1870. Pag. 178 Zeile 14 anstatt Kanelkafluss steht Kanelkefluss.

Zeile 16 anstatt Krasnostawschen steht Kresnostowschen.

Pag. 180 statt Alauda arvensis steht Alauda cristata.

Pag. 181 sollte stehen, statt Sitta caesia, Sitta uralensis.

Pag. 194 6. Zeile von unten muss 38 an Stelle von 39 und umgekehrt stehen.

Pag. 195 Zeile 9 sollte stehen anstatt

$$
\begin{aligned}
& 31-31-30 \text { die Ziffern } 34-35-34, \\
& 31--
\end{aligned}
$$

Pag. 198 Zeile 4 von unten: Der Autor, von dem ich sprach, ist Berge. - Ob aber die Beschreibung oder vielmehr Vergleichung der Pandion-Eier mit Milan-Eiern auf eigener Beobachtung beruht oder in F'olge von falsch bestimmten Eiern hervorgerufen wurde, wie so viele andere Fehler Berge's, kann ich natürlich nicht wissen. So gezeichnete Eier können nur grosse Seltenheiten sein. -

U man, $\frac{1}{13}$. Februar 1871.

*) Werde ich wohl auch mit der Zeit als Brutvogel find'n, da er im Nachbargouvernement in grosser Anzahl brütet. 